\title{
Cycling and at-rest stabilities of a complementary electrochromic device containing poly $(3,4-$ ethylenedioxythiophene) and Prussian blue ${ }^{\text {th }}$
}

\author{
Tsai-Shih Tung ${ }^{\mathrm{a}}$, Kuo-Chuan Ho ${ }^{\mathrm{a}, \mathrm{b}, *}$ \\ ${ }^{a}$ Department of Chemical Engineering, National Taiwan University, Taipei 10617, Taiwan \\ ${ }^{\mathrm{b}}$ Institute of Polymer Science and Engineering, National Taiwan University, Taipei 10617, Taiwan
}

Received 7 December 2004; accepted 13 February 2005

Available online 20 June 2005

\begin{abstract}
PEDOT-based electrochromic devices (ECDs) have been investigated intensively in recent years. In order to obtain an ECD having long cycle life, the counter electrode and electrolyte used should be compatible in the electrochemical environment. Prussian blue (PB) is proven to be electrochemically stable when cycling in non-aqueous solutions. Thus a new organicinorganic complementary ECD was assembled in combination with a PMMA-based gel polymer electrolyte. This ECD exhibited deep blue-violet when applying $-2.1 \mathrm{~V}$ and became light blue when applying $0.6 \mathrm{~V}$. Under these conditions, the transmittance of the ECD at $590 \mathrm{~nm}$ changed from $13.8 \%(-2.1 \mathrm{~V})$ to $60.5 \%(+0.6 \mathrm{~V})$ with a coloration efficiency of $338 \mathrm{~cm}^{2} / \mathrm{C}$. The cell retained $55 \%$ of its maximum transmittance window $\left(\Delta T_{\max }\right)$ after 50,640 repeated cycles. Moreover, the at-rest stability test revealed a transmittance window $(\Delta T)$ decay of $9.6 \%$ over a period of 107 days. Therefore, the proposed PEDOT-PB ECD may have potential for practical applications.
\end{abstract}

(C) 2005 Elsevier B.V. All rights reserved.

Keywords: At-rest stability; Coloration efficiency; Cycling stability; Electrochromic device; Poly(3,4ethylenedioxythiophene); Prussian blue

\footnotetext{
Paper presented at the Sixth International Meeting on Electrochromism (IME-6), Brno, Czech Republic, August 29-September 2, 2004.

*Corresponding author. Department of Chemical Engineering, National Taiwan University, Taipei 10617, Taiwan. Tel: +886223660739; fax: + 886223623040 .

E-mail address: kcho@ntu.edu.tw (K.-C. Ho).
} 


\section{Introduction}

Electrochromism [1] is a phenomenon with reversible and visible change in optical absorption in response to a DC voltage/current input. An electrochromic device (ECD) is composed of at least two layers of electrodes and one layer of electrolyte. The cell configuration may be solution, hybrid, or thin-film type [2]. If the two electrochromic (EC) materials offer an additive optical relationship, the ECD is referred to as complementary. During the last three decades, ECDs have been attractive for many applications such as displays [3], anti-glare rearview mirrors [4], secondary batteries [5], and solar-attenuated windows [6]. According to the types of EC materials, there are several systems reported in literature such as inorganic $\mathrm{WO}_{3}$-PB systems [7-9], inorganic-organic $\mathrm{WO}_{3}$-polyaniline systems [10,11], $\mathrm{WO}_{3}$-polypyrrole systems [12], organic solution system [13], and conducting polymers-based systems [14,15]. For comparison, conducting polymers-based systems have rapid optical response and high coloration efficiency (CE), while inorganic $\mathrm{WO}_{3}-\mathrm{PB}$ systems reported by Miyamoto et al. [7] and Ho [9] have larger transmittance window $(\Delta T)$. Except for some rare systems, most of the reported systems had problems of long-term cycling stability. Even if an ECD has good initial performance, such as high optical contrast or rapid response, it would limit the possibilities to bring the EC products to the markets before the cycling and at-rest stabilities are solved. Thus, resolving the stability issue is a crucial task. If an ECD is thought to be electrochemically and thermally stable over a long period of time, the good compatibility of the two EC materials with the electrolyte is required.

With the continuing development of the conducting polymers [16], many conducting polymers, such as polyaniline, polypyrrole, polythiophene and their derivatives, have been studied for the EC applications. Recently, a new conducting polymer, poly(3,4-ethylenedioxythiophene) (designated as PEDOT), was synthesized in Bayer AG research laboratories and commercialized. PEDOT possessed not only a high conductivity of $300 \mathrm{~S} / \mathrm{cm}$, but also exhibited good electrochemical and thermal stabilities [17,18]. With these attractive properties, PEDOT has been researched for many applications such as antistatic coatings [19], capacitors [18], light-emitting diodes [20], photoelectrochemical cells [21], biosensors [22], and ECDs [23-28]. PEDOT exhibits deep blue-violet in its neutral state. Upon doping, it changes to light blue, so it is EC in nature and is attractive to EC applications. Gustafsson et al. [23] was the first to report the PEDOT-based ECD with inorganic $\mathrm{Li}_{y} \mathrm{VO}_{x}$ as the counter electrode in 1994. They reported that the transmittance of the ECD at $585 \mathrm{~nm}$ changed from $61 \%(+0.5 \mathrm{~V})$ to $25 \%(-1.5 \mathrm{~V})$, with a $\Delta T$ of $36 \%$ and a high $\mathrm{CE}$ of ca. $560 \mathrm{~cm}^{2} / \mathrm{C}$. The cell shows good reversibility, as evidenced by completing several thousand electrochemical cycles. In 1996, Sapp et al. [24] reported two dualpolymer ECDs based on PEDOT; the counter electrodes used were poly[3,6-bis(2(3,4-ethylenedioxythiophene))- $N$-methylcarbazole] and polyaniline (PANI). The two cells were both opaque violet in the colored state and pale transparent green in the bleached state. The PEDOT-PANI ECD exhibited a $\Delta T$ of $45 \%$ at $620 \mathrm{~nm}$ with a limited cycle life of about 50-100 cycles. The symmetrical and wide range of 
operating potentials may be what causes the serious $\Delta T$ decay. Subsequently, the same group assembled 12 kinds of cells by using PEDOT or PEDOT derivatives [25]. They claimed that one of the devices possessed an extremely high CE of up to $1413 \mathrm{~cm}^{2} / \mathrm{C}$ and retained $60 \%$ of the original optical response after $10^{4}$ double potential steps. De Paoli et al. [26,27] reported PEDOT-based ECDs using polypyrrole and poly (o-methoxy aniline) as the counter electrodes. These two ECDs showed high $\Delta T(52 \%$ and $75 \%$, respectively) at $640 \mathrm{~nm}$. However, the decay of the $\Delta T$ was rapid over 100 cycles. In 2001, DeLongchamp and Hammond [28] proposed a new ECD using layer-by-layer method to form the EC electrodes. Although the $\Delta T$ of the device was low $(24 \%$ at $660 \mathrm{~nm})$, the optical response was retained after 35,000 cycles. Of those ECDs mentioned, only De Paoli et al. [27] reported spectra decay percentages. Table 1 summarizes the performance of the referenced PEDOT-based ECDs.

Although PEDOT has been proven to possess good electrochemical stability, a stable counter electrode pairing with PEDOT is needed in making the cell stable enough for long-term switching. The counter electrode acts not only as the charge compensating electrode but also should be compatible with the PEDOT in terms of electrochemical cycling in the same electrolyte. Although most of the counter electrodes shown in Table 1 are conducting polymers, the compatibility and cycling stability issues are still needed to be overcome. Apart from conducting polymers used as the counter electrode in ECDs, the inorganic Prussian blue (PB, iron (III) hexacyanoferrate (II)) $[29,30]$ can be another choice. With regard to the use as a complementary EC material for ECDs, PB, which is characterized by a polyelectrochromic property and exhibits four corresponding redox states [31], has been investigated intensively. From the most reduced to the most oxidized state, the four redox states of PB are the colorless Everitt's salt (ES), PB, Berlin green (BG), and Prussian yellow (PY). PB can be cycled reversibly for several thousand times both in appropriate aqueous electrolyte [32] and in $\mathrm{WO}_{3}-\mathrm{PB}$ polymeric ECDs $[9,33]$. Moreover, $\mathrm{PB}$ has also proven to have good electrochemical stability in non-aqueous solvents [34,35]. In this work, a new organic-inorganic complementary ECD was assembled by using both PEDOT and PB thin-film electrodes.

A poly(methyl methacrylate)-based (PMMA-based) gel polymer electrolyte [36,37] was incorporated into the new PEDOT-PB ECD. The electrochemical and

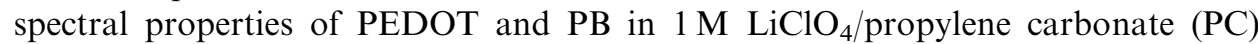
are discussed in this paper. The performance of the new ECD was characterized by the two-electrode chronoamperometry. The results show that PEDOT and PB exhibit good electrochemical stability in an organic environment, and the ECD has a $\Delta T$ value of ca. $47 \%$ at $590 \mathrm{~nm}$. In addition, the PEDOT-PB ECD has a reasonable coloration efficiency of ca. $338 \mathrm{~cm}^{2} / \mathrm{C}$ at $590 \mathrm{~nm}$. The ECD shows good dynamic cycling stability and at-rest stability. After a total of 50,640 cycling test, $\Delta T$ at $590 \mathrm{~nm}$ retained $55 \%$ of its maximum value. As for the at-rest test, the decay in $\Delta T$ was only $9.56 \%$ after a period of 107 days. The good long-term stability may provide the foundation for making this ECD into a real practice. 


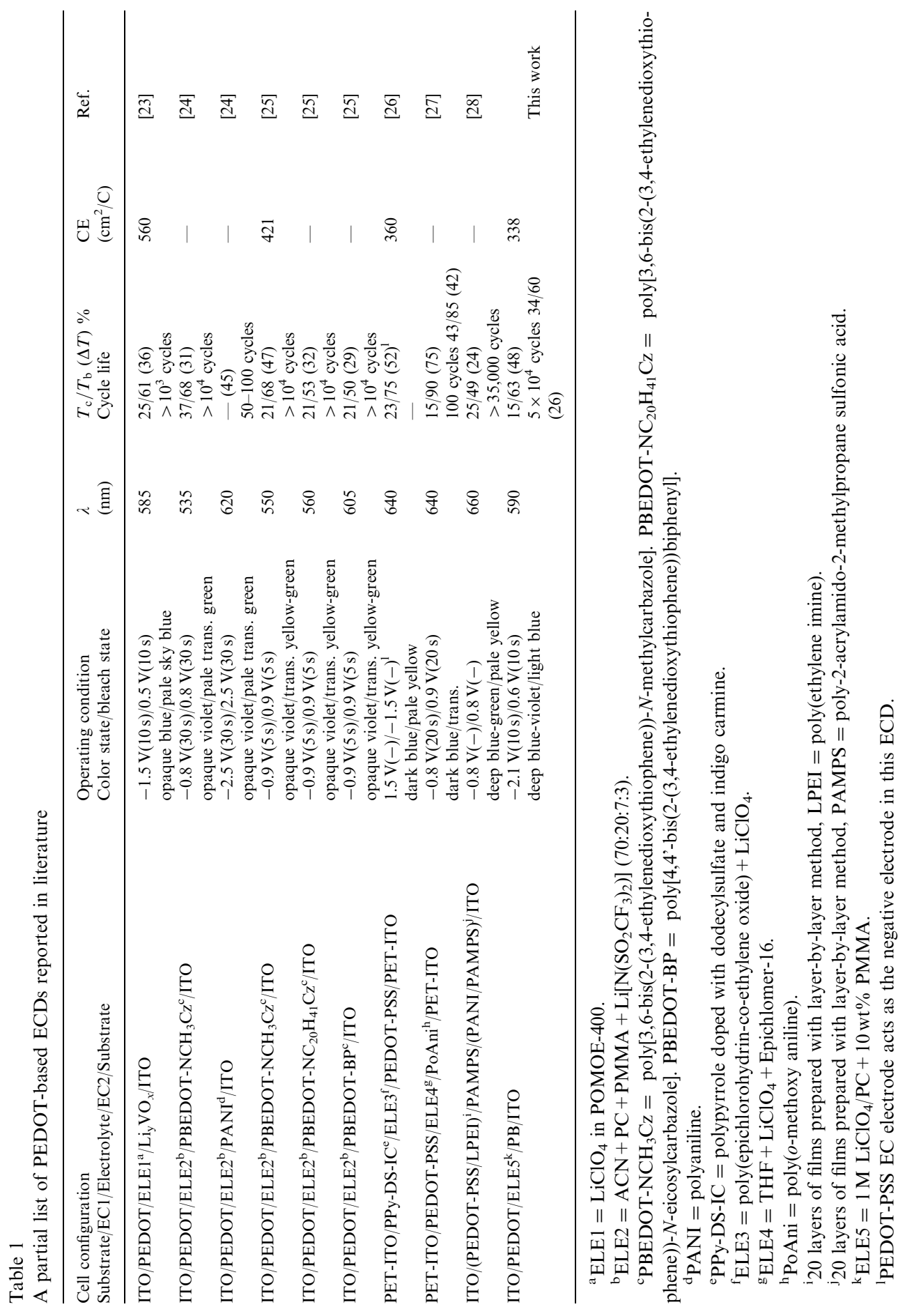




\section{Experimental}

\subsection{Materials}

The solvents, acetonitrile (ACN) and PC, used in this work were purified before using. They were bubbled with nitrogen gas $\left(\mathrm{N}_{2}\right)$ for $10 \mathrm{~min}$, dehydrated with $4 \AA$ molecular sieves and stored in $\mathrm{N}_{2}$ atmosphere prior to use. Lithium perchlorate $\left(\mathrm{LiClO}_{4}\right)$ was dissolved into $\mathrm{ACN}$ and melted at $110^{\circ} \mathrm{C}$, under vacuum for $24 \mathrm{~h}$. PMMA (weight average $\mathrm{MW}=996,000$ ) was dried at $100^{\circ} \mathrm{C}$ under vacuum for $15 \mathrm{~h}$. The recrystallized $\mathrm{LiClO}_{4}$ and dehydrated PMMA were stored in $\mathrm{N}_{2}$ atmosphere prior to use. Other chemicals (tetrabutylammonimun perchlorate (TBAP), $\mathrm{AgNO}_{3}$, $\mathrm{KCl}, \mathrm{HCl}, \mathrm{FeCl}_{3} \cdot 6 \mathrm{H}_{2} \mathrm{O}$, and $\left.\mathrm{K}_{3} \mathrm{Fe}(\mathrm{CN})_{6}\right)$ were used as received. The electrode potential recorded was against a homemade $\mathrm{Ag} / \mathrm{Ag}^{+}$non-aqueous reference electrode. The $\mathrm{Ag} / \mathrm{Ag}^{+}$reference electrode contains a solution of $10 \mathrm{mM} \mathrm{AgNO}_{3}$ and $0.1 \mathrm{M}$ TBAP in $\mathrm{ACN}$. The calibrated potential of the $\mathrm{Ag} / \mathrm{Ag}^{+}$reference electrode is $0.48 \mathrm{~V}$ vs. NHE.

\subsection{Preparation of the electrochromic thin-film electrodes}

Optically transparent ITO glass substrates $\left(R_{\text {sh }}=20 \Omega /\right.$ sq., RiTdisplay Corporation, Hsinchu Industrial Park, Taiwan) were used for the deposition of EC films. Before use, the ITO substrates $\left(3.0 \times 4.0 \times 0.2 \mathrm{~cm}^{3}\right)$ were ultrasonically cleaned in a $0.1 \mathrm{M} \mathrm{HCl}$ solution for $3 \mathrm{~min}$. They were ultrasonically re-cleaned for $3 \mathrm{~min}$ in deionized water (DIW) and dried in air. The insulating epoxy tapes (3 M Company, $0.14 \mathrm{~mm}$ thick) were pasted around the four edges of the ITO glass to maintain the same electroactive area of $2.0 \times 2.0 \mathrm{~cm}^{2}$ on each electrode. Later, a piece of $\mathrm{Cu}$ tape ( $3 \mathrm{M}$ Company, $3.0 \times 0.5 \mathrm{~cm}^{2}$ ) was applied at one edge of the ITO surface as the bus bar. A three-electrode electrochemical cell was set up to deposit the EC thin films using the ITO glass substrate as the working electrode, a platinum plate counter electrode and the $\mathrm{Ag} / \mathrm{Ag}^{+}$reference electrode. The experiments were conducted in air at room temperature and controlled by a potentiostat/galvanostat (Eco-Chemie, Autolab, PGSTAT30). The deposition solution for PEDOT was composed of $10 \mathrm{mM}$ 3,4-ethylenedioxythiophene (EDOT) monomer and $0.1 \mathrm{M}$ $\mathrm{LiClO}_{4}$ in ACN. The PEDOT thin films were electropolymerized onto the ITO glass substrates by applying a potential at $1.2 \mathrm{~V}$ (vs. $\mathrm{Ag} / \mathrm{Ag}^{+}$) with a platinum counter electrode until a charge capacity of $25 \mathrm{mC} / \mathrm{cm}^{2}$ was passed, in order to control the film thickness. The average thickness of the PEDOT films was $155 \mathrm{~nm}$ as measured using a profilometer (Sloan Dektak, model 3030). The as-deposited PEDOT thin-film electrodes were rinsed with ACN and dried in air prior to use. The PB thin-film electrodes were deposited galvanostatically. The composition of the plating solution was $10 \mathrm{mM} \mathrm{FeCl}_{3} \cdot 6 \mathrm{H}_{2} \mathrm{O}_{(\mathrm{aq})}, 10 \mathrm{mM} \mathrm{K}_{3} \mathrm{Fe}(\mathrm{CN})_{6(\mathrm{aq})}, 0.1 \mathrm{M}$ $\mathrm{KCl}_{(\mathrm{aq})}$, and $0.1 \mathrm{M} \mathrm{HCl}(\mathrm{aq})$. Before the deposition, the mixed plating solution was bubbled with $\mathrm{N}_{2}$ for $10 \mathrm{~min}$ to reduce the $\mathrm{O}_{2}$ content of the solution. The deposition was done by applying a cathodic current density of $20 \mu \mathrm{A} / \mathrm{cm}^{2}$ onto the ITO glass substrates and the deposition time was controlled either at $120 \mathrm{~s}$ for 
the use in cell assembly or $300 \mathrm{~s}$ for the measurement of the absorbance spectra. The as-deposited PB electrodes were rinsed with DIW, dried under the flow of $\mathrm{N}_{2}$, and stored in air for at least one day before using.

\subsection{Preparation of gel polymer electrolytes and cell assembly}

The ECD was assembled with the PEDOT and PB electrodes by incorporating a PMMA-based gel polymer electrolyte under $\mathrm{N}_{2}$ atmosphere. The PMMA-based gel polymer electrolyte was prepared according to the literatures [36,37]. $\mathrm{LiClO}_{4}$ salt was dissolved into PC. Then $10 \mathrm{wt} \%$ PMMA, which was based on $1.0 \mathrm{M} \mathrm{LiClO}_{4} / \mathrm{PC}$ solution, was added and well-stirred. Finally, the solution was slowly heated until a transparent gel was formed. Before the cell assembly, both the PEDOT and PB electrodes were cycled several times by the cyclic voltammetric (CV) method in $1.0 \mathrm{M}$ $\mathrm{LiClO}_{4} / \mathrm{PC}$ solution under $\mathrm{N}_{2}$ atmosphere to ensure the proper function of the ion insertion and extraction. After the cycles, the PEDOT and the PB electrodes were stepped to doping state and colorless ES state by applying $0.3 \mathrm{~V}$ and $-0.9 \mathrm{~V}$ for $60 \mathrm{~s}$, respectively. Following this potential pretreatment, the transparent gel polymer electrolyte was poured onto the PEDOT electrode, and the PB electrode was placed on top. Subsequently, the three layers were carefully sandwiched together to form a solid-state EC cell. The cell gap was controlled at $0.28 \mathrm{~mm}$ with a spacer tape. Finally, the cell was sealed with a Torr Seal ${ }^{\circledR}$ (Varian) cement around the four edges of the ITO glass.

\subsection{Electrochemical and spectral measurements for the electrodes and stability tests for the $E C D$}

The PEDOT and PB EC electrodes were characterized electrochemically in $1.0 \mathrm{M}$ $\mathrm{LiClO}_{4} / \mathrm{PC}$ by the three-electrode $\mathrm{CV}$ method. The $\mathrm{CV}$ was performed by using the above-mentioned potentiostat/galvanostat. Both the PEDOT and PB thin-film electrodes were separately connected to a potentiostat/galvanostat and placed in a spectrophotometer (Shimadzu, model UV-1601PC) to collect the absorbance spectra ranging between 350 and $1100 \mathrm{~nm}$ at different equilibrated potentials in $1.0 \mathrm{M}$ $\mathrm{LiClO}_{4} / \mathrm{PC}$ solution. In the same manner, the absorbance spectra of the ECD were also measured at different equilibrated applied voltages (PEDOT vs. PB). The dynamic transmittance responses of the PEDOT electrode and the ECD at $590 \mathrm{~nm}$ were measured in situ by a double potential method. The dynamic cycling stability test of the ECD was characterized by the two-electrode chronoamperometry with a multi-channel battery testing system (Maccor, model 2300). The applied voltage (PEDOT vs. PB) was $-2.1 \mathrm{~V}$ for $10 \mathrm{~s}$ and changed to $0.6 \mathrm{~V}$ for $10 \mathrm{~s}$ at each cycle. The in situ transmittance spectra at $590 \mathrm{~nm}$ were recorded continuously for the first 1000 cycles, and the spectra were collected at specific cycle after 1000 cycles. Additionally, the at-rest stability of the ECD was characterized by the same method. The only difference was that the switching time was $30 \mathrm{~s}$ for each step, and the transmittance data were collected at specific day. 


\section{Results and discussion}

\subsection{Electrochemical and spectral properties of PEDOT and PB thin-film electrodes}

\subsubsection{Electrochemical properties of PEDOT and PB thin-film electrodes}

The typical CVs of PEDOT and PB EC electrodes are shown in Fig. 1. They were cycled in $1.0 \mathrm{M} \mathrm{LiClO}_{4} / \mathrm{PC}$ solution under $\mathrm{N}_{2}$ atmosphere at a scan rate of $100 \mathrm{mV} / \mathrm{s}$. According to Fig. 1, PEDOT thin-film electrodes show two oxidative and reductive peaks in the cycling potential range. The two oxidative peaks locate at ca. -0.89 and $-0.12 \mathrm{~V}$, and the reductive peaks locate at ca. -1.04 and $-0.29 \mathrm{~V}$. However, the first oxidative peak at $-0.89 \mathrm{~V}$ is not obvious. The electrochemical behavior is similar to the results reported in the literature [38]. When PEDOT is doped in the positive potential range, the charge compensation of anions occurs and exhibits a capacitive characteristic. PEDOT is a cathodically coloring EC material; it shows deep blueviolet in the neutral state, while upon doping, it changes to light blue. On the other hand, $\mathrm{PB}$ is colorless in the ES state at $-0.9 \mathrm{~V}$ and blue in the PB state at $0.4 \mathrm{~V}$. To avoid the second redox couple formation in $\mathrm{PB}$, the upper oxidative potential is controlled at $0.4 \mathrm{~V}$. With the results of the CVs, PEDOT and PB thinfilm electrodes fulfill the requirement of a complementary ECD. Moreover, the simplified working principle of the complementary PEDOT-PB ECD containing $\mathrm{LiClO}_{4}$ salt can be represented by Eqs. (1) and (2) for PEDOT and PB electrodes,

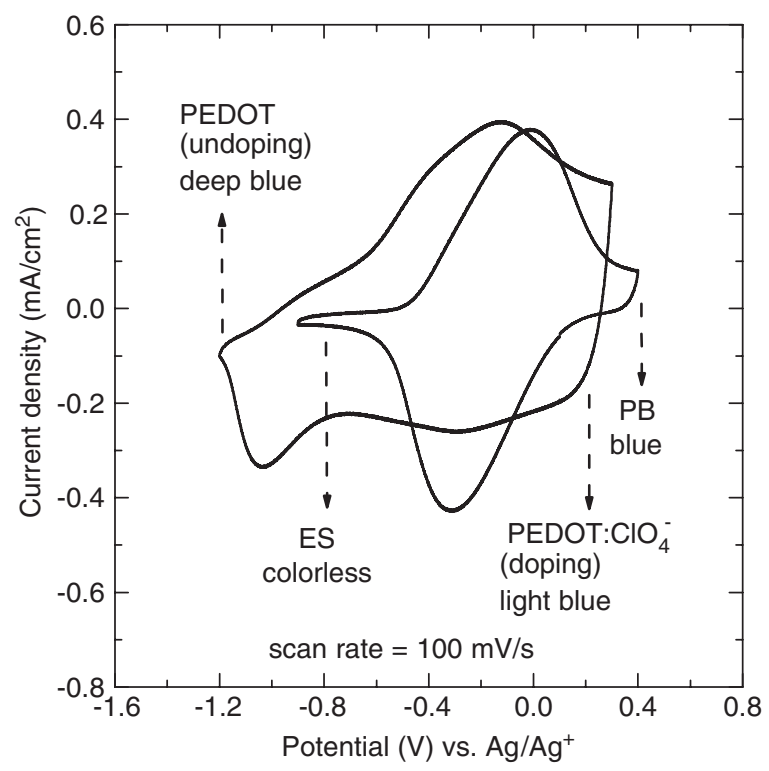

Fig. 1. CVs for the PEDOT and PB electrodes scanned in $1.0 \mathrm{M} \mathrm{LiClO}_{4} / \mathrm{PC}$ under $\mathrm{N}_{2}$ atmosphere at a scan rate of $100 \mathrm{mV} / \mathrm{s}$. The area of the electrode is $2.0 \times 2.0 \mathrm{~cm}^{2}$. 
respectively, as follows:

$$
\begin{array}{ll}
\mathrm{PEDOT}^{n+}: n \mathrm{ClO}_{4}^{-}+\mathrm{ne}^{-} & \leftrightarrow \\
\text { (Doping state, light blue) } & \text { (Undoping state, deep blue) }
\end{array}
$$

$$
\begin{array}{lcc}
\mathrm{Li}_{2} \mathrm{Fe}^{\mathrm{II}}\left[\mathrm{Fe}^{\mathrm{II}}(\mathrm{CN})_{6}\right] \leftrightarrow & \mathrm{LiFe}^{\mathrm{III}}\left[\mathrm{Fe}^{\mathrm{II}}(\mathrm{CN})_{6}\right]+\mathrm{Li}^{+}+\mathrm{e}^{-} \\
(\mathrm{ES}, \text { colorless }) & (\mathrm{PB}, \text { blue }),
\end{array}
$$

(PB, blue),

where ES is the Everitt's salt, $n$ is the stoichometric number of the counter ions. Thus the overall EC process in the ECD can be represented by adding Eqs. (1) and (2), as

$$
\begin{array}{lc}
\mathrm{PEDOT}^{n+}: n \mathrm{ClO}_{4}^{-}+n \mathrm{ES} & \leftrightarrow \\
\text { (Bleach state, light blue) } & \text { (Color state, deep blue) }
\end{array}
$$

\subsubsection{Spectral properties of PEDOT and PB thin-film electrodes}

Fig. 2 shows the results of the absorbance spectra for the PB thin-film electrode equilibrated at different potentials in a $1.0 \mathrm{M} \mathrm{LiClO}_{4} / \mathrm{PC}$ solution. In the visible region, the intensity of the absorbance peak increases as the applied potential increases. The maximum absorption occurs at $690 \mathrm{~nm}$, which is the same characteristic wavelength when switching PB in an aqueous electrolyte [31]. The

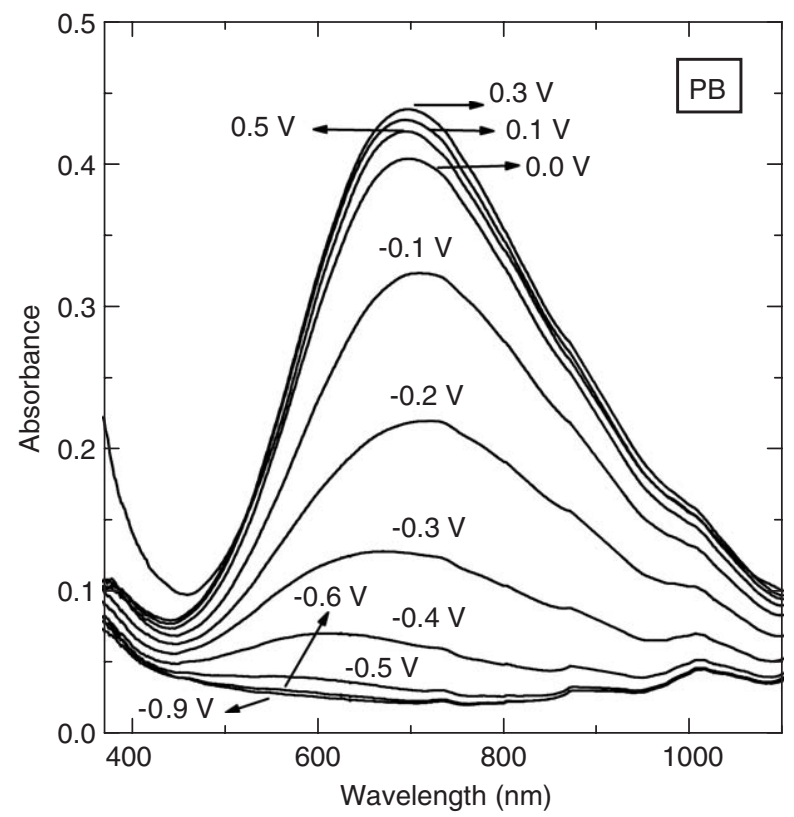

Fig. 2. Absorbance spectra of the PB electrode equilibrated in $1 \mathrm{M} \mathrm{LiClO}_{4} / \mathrm{PC}$ at different applied potentials. The PB film was deposited at a constant current density of $20 \mu \mathrm{A} / \mathrm{cm}^{2}$ for $300 \mathrm{~s}$. 
PB spectra show no absorption characteristics when the applied potential is more negative than $-0.6 \mathrm{~V}$, which is consistent with the results of CVs. In contrast, when the applied potential is more positive than $0.3 \mathrm{~V}$, the absorption starts to decrease due to the formation of BG. That is why one needs to control the potential, only to allow for the formation of the first redox couple. Similarly, the spectra of PEDOT equilibrated at different potentials are shown in Fig. 3. The spectral behavior is similar to those reported in Ref. [39]. The absorbance in the neutral state, which starts to increase at $760 \mathrm{~nm}$, implies that the band gap of PEDOT is ca. $1.6 \mathrm{eV}$. The neutral PEDOT exhibits a high absorbance throughout the visible region, and the maximum absorptive peaks locate at 590 and $620 \mathrm{~nm}$. The wavelengths, correspond to deep blue-violet region, are especially sensitive to human eyes. Upon doping, the absorption in the visible region decreases; however, another absorption peak appears at ca. $885 \mathrm{~nm}$. Carlberg et al. [40] explained this as the formation of the bipolaron state of PEDOT. As the applied potential is increased further, the absorption peaks at 620 and $885 \mathrm{~nm}$ disappear and another low-energy absorption increases in the IR region. These are the characteristics of the low band-gap conducting polymers, making PEDOT a good cathodically EC material attractive to ECD applications. When the applied potential is more positive than $0.2 \mathrm{~V}$, it is also found that PEDOT results in a capacitive charging and does not change the absorbance in the visible region.

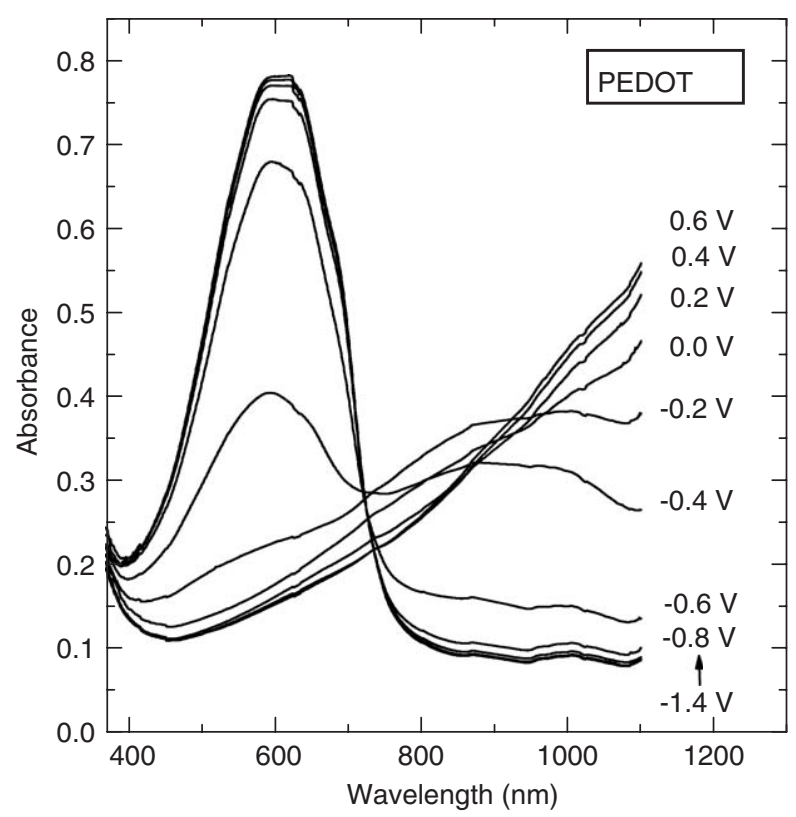

Fig. 3. Absorbance spectra of the PEDOT electrode equilibrated in $1.0 \mathrm{M} \mathrm{LiClO}_{4} / \mathrm{PC}$ at different applied potentials. The PEDOT film was deposited by applying a potential of $1.2 \mathrm{~V}$ ( $\mathrm{vs} . \mathrm{Ag} / \mathrm{Ag}^{+}$), with a controlled charge density of $25 \mathrm{mC} / \mathrm{cm}^{2}$. 


\subsubsection{Transmittance response and coloration efficiency of PEDOT}

As the deposited charge capacity of PB used in the ECD is only $2.40 \mathrm{mC} / \mathrm{cm}^{2}$, the EC contribution of PB in the PEDOT-PB ECD is less important, as compared to that of PEDOT. In this section, we will discuss the dynamic transmittance and coloration efficiency of the PEDOT electrode only. Because the maximum absorbance change for PEDOT occurs at ca. $590 \mathrm{~nm}$, Fig. 4 shows the in situ transmittance change at $590 \mathrm{~nm}$ in response to the applied potentials. The coloring potential $\left(V_{\mathrm{c}}\right)$ was set to $-1.2 \mathrm{~V}$, and the bleaching potential $\left(V_{\mathrm{b}}\right)$ was set to $1.0 \mathrm{~V}$, with switching intervals of $10 \mathrm{~s}$. From the figure, the maximum $\Delta T$ at $590 \mathrm{~nm}$ is ca. $50 \%$. This value is close to those reported in Refs. [41,42]. The response of the doping process is faster than that of the undoping one. Moreover, as the current response of the EC material is rapid, the estimation of the inserted charge should be recorded with extra care [23]. Under certain circumstances, if the inserted charge is underestimated, it is very likely that the calculated coloration efficiency would be overestimated by two or three times. Thus we have recorded data for the current-time $(I-t)$ response with an interval of $0.01 \mathrm{~s}$ by the above-mentioned potentiostat/galvanostat to avoid the underestimation of the inserted charge. The inserted charge density was obtained from the integration of the $I-t$ curve and was ca. $2.40 \mathrm{mC} / \mathrm{cm}^{2}$, which was very close to the reported value of $2.68 \mathrm{mC} / \mathrm{cm}^{2}$ at $95 \%$ of the full switch [42]. The charge density passed at $95 \%$ of the full optical density change is used for reporting the coloration efficiency since the majority of the color change has taken place and the last $5 \%$ is difficult to perceive with the naked eye.

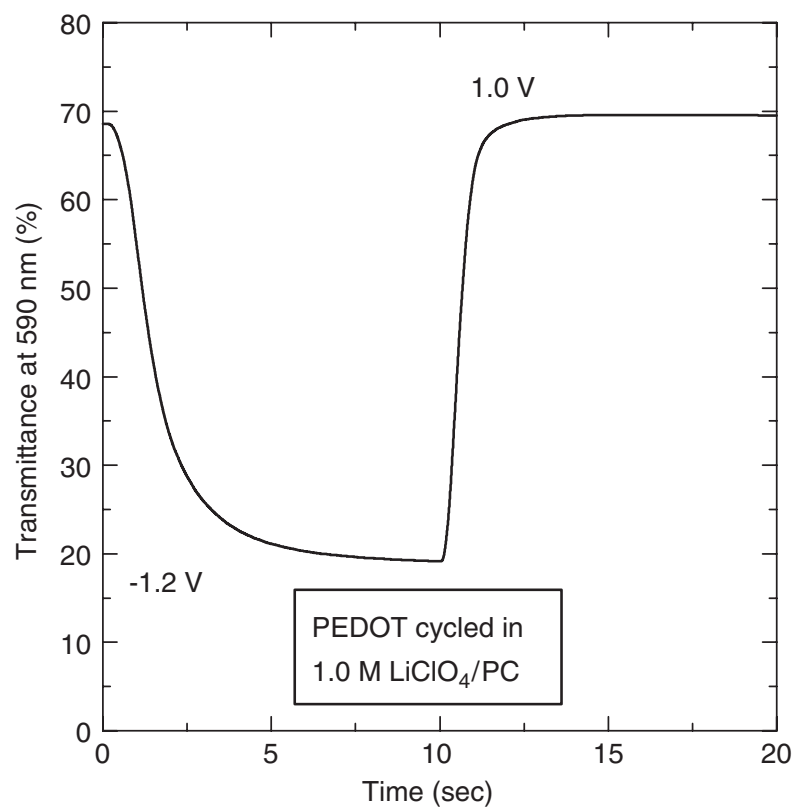

Fig. 4. The transmittance response at $590 \mathrm{~nm}$ for a PEDOT electrode cycled in $1.0 \mathrm{M} \mathrm{LiClO}_{4} / \mathrm{PC}$. The applied potentials were $-1.2 \mathrm{~V}(10 \mathrm{~s})$ for coloring and $1.0 \mathrm{~V}(10 \mathrm{~s})$ for bleaching. 
Following this practical observation, the anodic coloration efficiency of PEDOT at $590 \mathrm{~nm}$ was calculated to be ca. $225 \mathrm{~cm}^{2} / \mathrm{C}$ (equilibrated at $-1.2 \mathrm{~V}$ for $10 \mathrm{~s}$, then stepped to $1.0 \mathrm{~V}$ ), and that of the cathodic one was ca. $120 \mathrm{~cm}^{2} / \mathrm{C}$ (equilibrated at $0.6 \mathrm{~V}$ for $10 \mathrm{~s}$, then stepped to $-1.2 \mathrm{~V}$ ). Such lower cathodic coloration efficiency may be attributed to the extra charge consumed by side reactions in the negative applied potential.

\subsection{Operational performance of the PEDOT-PB ECD}

\subsubsection{Spectral characterization and dynamical response of the ECD}

The high coloration efficiency of PEDOT would make it very attractive to ECD applications from the viewpoint of the low-required power consumption. However, in order to obtain a workable and stable ECD, the choices of counter electrode and electrolyte are crucial. As outlined in Table 1, there are many PEDOT-based ECDs reported in recent years using a wide variety of counter electrodes. Most of them are organic, thus forming the dual polymer ECDs. Nevertheless, long-term stability may still be a problem. In this work, PB was chosen as the counter electrode because it is electrochemically active and stable, not only in aqueous systems [32] but also in nonaqueous systems $[34,35]$. The PMMA-based gel polymer electrolyte has been proven to possess high ionic conductivity; stable electrochemically and thermally [36,37] when the $\mathrm{LiClO}_{4}$ salt and PC are used. In addition to the advantageous properties of the gel, the lithium salt in non-aqueous solvents does not have the insertion and extraction problem that seems to cause irreversibility for PB in aqueous solutions, in which serious hydration of lithium ions occurs [34]. Therefore, an ECD made of PEDOT and PB thin films with a PMMA-based gel electrolyte was successfully fabricated. Fig. 5 shows the in situ spectra of the ECD recorded between 370 and $1000 \mathrm{~nm}$. The voltages reported in Fig. 5, and the rest of the device, are PEDOT with respect to $\mathrm{PB}$. In order to achieve the charge balance between the two electrodes in the cell, the thickness of PB was carefully controlled, as mentioned in the Experimental section. The spectra of the assembled PEDOT-PB ECD, as shown in Fig. 5, were similar to those of the PEDOT in Fig. 3. From Fig. 5, the maximum absorption occurs at $625 \mathrm{~nm}$, while the maximum absorbance change is at $590 \mathrm{~nm}$. According to Fig. 1, when PEDOT thin-film electrode acts as the positive electrode in the assembled ECD, the cell exhibits deep blue-violet when the applied voltage is more negative. At a negative applied cell voltage, PEDOT is at its neutral state, and the negative electrode (PB) is in the blue state; so both are in the colored states. In addition, absorbance in the visible region reaches a maximum when the applied voltage is ca. $-2.1 \mathrm{~V}$. On the other hand, the ECD exhibits light blue as the applied voltage is higher than $0.0 \mathrm{~V}$, and reaches a saturated absorbance at $0.6 \mathrm{~V}$. It is therefore expected that when the ECD is stepped between -2.1 and $0.6 \mathrm{~V}$, a maximum $\Delta T$ at $590 \mathrm{~nm}$ can be achieved.

\subsubsection{Credible measurement for the coloration efficiency of the ECD}

The typical in-situ transmittance response measured at $590 \mathrm{~nm}$ and the corresponding $I-t$ transient response of the ECD are shown in Fig. 6(a) and (b), 


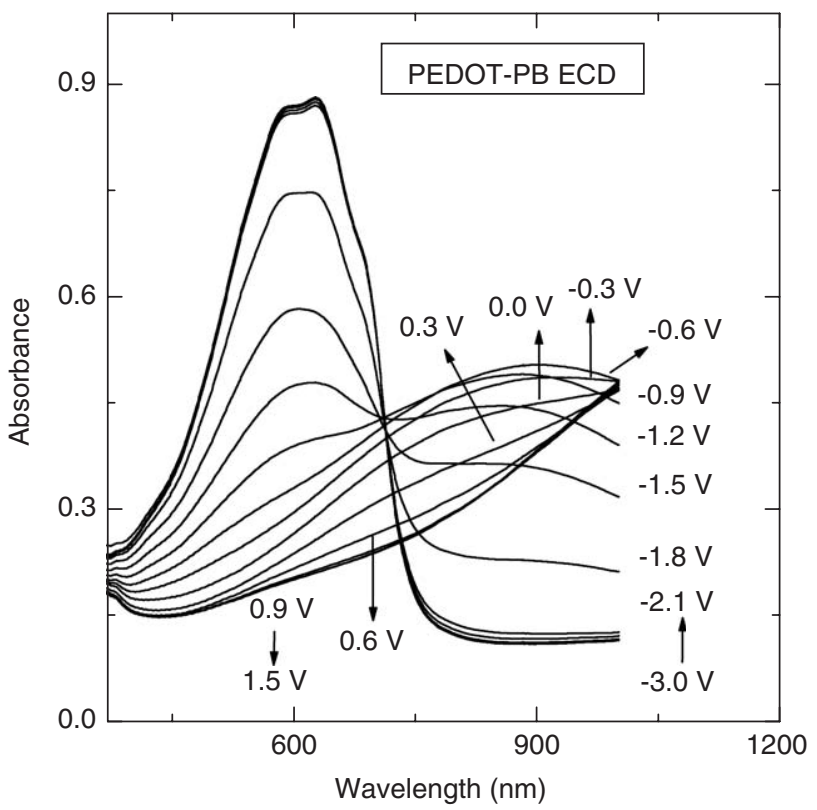

Fig. 5. Absorbance spectra of the PEDOT-PB ECD switched at different applied voltages. The voltage is the potential difference between the PEDOT electrode and the PB electrode (PEDOT vs. PB). The PEDOT electrode acts as the positive electrode.
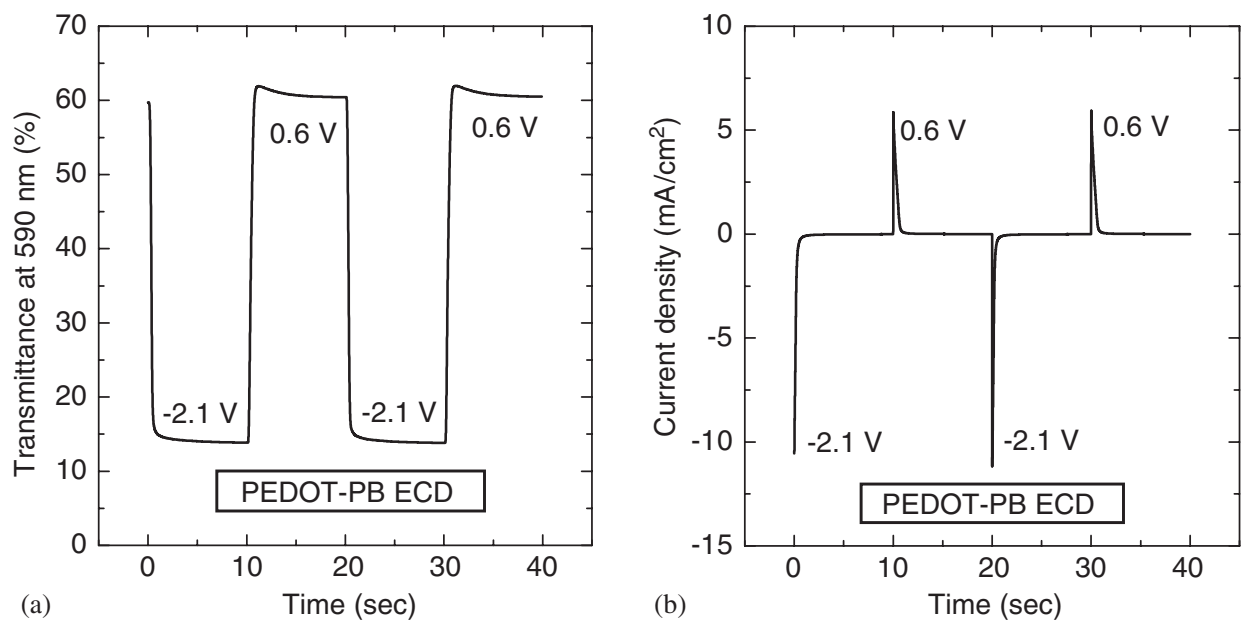

Fig. 6. (a) The in situ transmittance response of the cell at $590 \mathrm{~nm}$. The applied voltages were $V_{\mathrm{c}}=-2.1 \mathrm{~V}$ $(10 \mathrm{~s})$ for coloring and $V_{\mathrm{b}}=0.6 \mathrm{~V}(10 \mathrm{~s})$ for bleaching and (b) the corresponding current density-time relationship of the cell in response to the applied voltages. The data were recorded with a time interval of $0.005 \mathrm{~s}$. 
respectively. The applied voltages are $V_{\mathrm{c}}=-2.1 \mathrm{~V}$ for coloring and $V_{\mathrm{b}}=0.6 \mathrm{~V}$ for bleaching, with an interval of $10 \mathrm{~s}$ each. The ECD exhibits a reversible transmittance response of ca. $13.8 \%$ in the colored state and ca. $60.5 \%$ in the bleached state, resulting in a $\Delta T$ of $46.7 \%$. There is only a small $\Delta T$ loss compared to that of the PEDOT, as revealed in Fig. 4. The reductive peak current is larger than that of the anodic one, as judged by Fig. 6(b). This implies that the electron transfer is faster in the undoping process due to the metallic state of PEDOT. In addition, the integrated area under the $I-t$ curve (recorded time interval $=0.005 \mathrm{~s}$ ) gives the inserted charge density of ca. $1.9 \mathrm{mC} / \mathrm{cm}^{2}$ for the doping process and $2.0 \mathrm{mC} / \mathrm{cm}^{2}$ for the undoping process. The calculated coloration efficiencies of the ECD at $590 \mathrm{~nm}$, both in doping and undoping processes, are $338 \mathrm{~cm}^{2} / \mathrm{C}\left(\log (60.5 / 13.8) / 0.0019=338 \mathrm{~cm}^{2} / \mathrm{C}\right)$ and $321 \mathrm{~cm}^{2} / \mathrm{C} \quad\left(\log (60.5 / 13.8) / 0.002=321 \mathrm{~cm}^{2} / \mathrm{C}\right)$, respectively, as calculated from Fig. 6(a) and (b). In order to avoid the underestimation of the inserted charge of the ECD, the choice of the time interval for the recorded current is important. Fig. 7(a) and (b) reveal that both the inserted charge density and the calculated coloration efficiency of another ECD, being operated under the same condition $\left(V_{\mathrm{c}}=-2.1 \mathrm{~V}(10 \mathrm{~s})\right.$ and $\left.V_{\mathrm{b}}=0.6 \mathrm{~V}(10 \mathrm{~s})\right)$ as that of the ECD in Fig. 6, are dependent of the time interval of the recorded data taken in the $I-t$ response. From Fig. 7(a), one finds that the inserted charge density reaches a near constant value as the recorded time interval decreases. The faster the current response of the ECD, the smaller the recorded time interval is needed to capture the peak current and obtain the exact inserted charge. From Fig. 7(b), one sees that the calculated coloration efficiency approaches a constant value as the recorded time interval decreases, and we concluded that the calculated coloration efficiency of our ECD is reasonable. Although the high coloration efficiency obtained in the PEDOT-PB ECD is
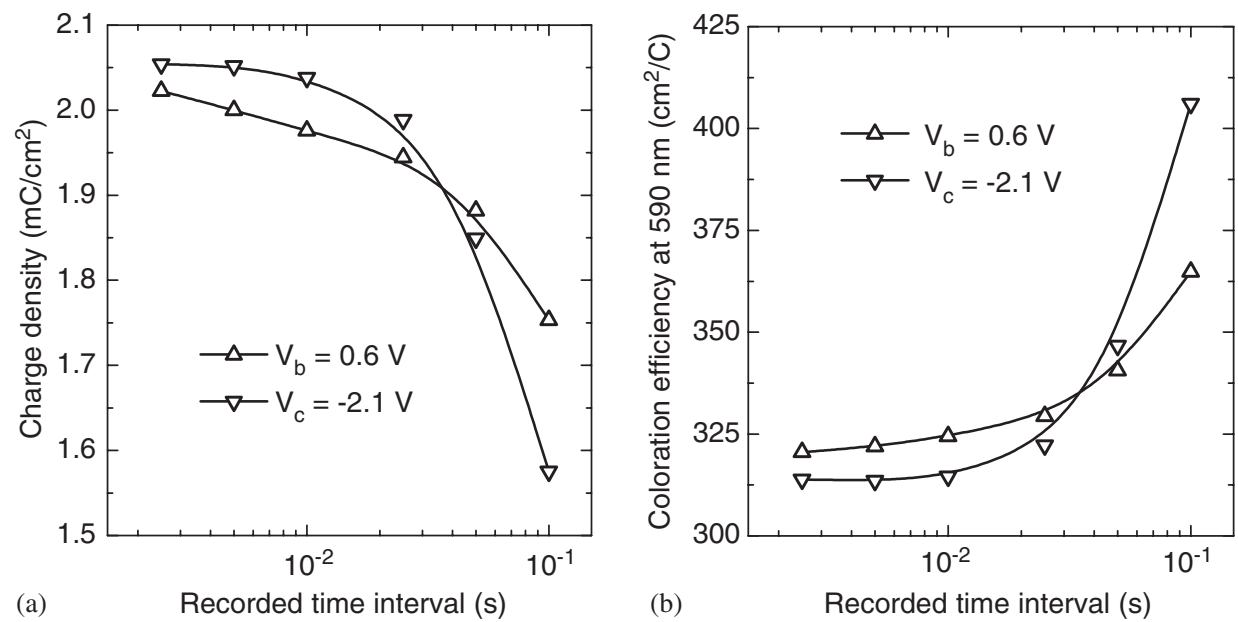

Fig. 7. (a) The passed charge densities of the ECD as a function of the recorded time interval in the $I-t$ response and (b) the calculated coloration efficiencies of the ECD as a function of the time interval recorded in the $I-t$ response. 
attractive, cycling and at-rest stabilities are even more important in real practice. The results of the long-term stability for the PEDOT-PB ECD are discussed below.

\subsection{Long-term cycling stability and at-rest stability of the ECD}

\subsubsection{Long-term cycling stability of the ECD}

Fig. 8 plots the in situ transmittances in the bleached state $\left(T_{\mathrm{b}}\right)$, colored state $\left(T_{\mathrm{c}}\right)$, and transmittance window $(\Delta T)$ of the ECD at $590 \mathrm{~nm}$ as a function of the cycling number $(N)$. The ECD was tested up to 50,640 cycles. During the cycling tests, the applied voltages were set at $V_{\mathrm{c}}=-2.1 \mathrm{~V}$ for coloring and $V_{\mathrm{b}}=0.6 \mathrm{~V}$ for bleaching, with the time interval of each step being set at $10 \mathrm{~s}$. It is apparent that the variation of the $\Delta T$ can be divided into four stages. During the first 60 cycles $(N \leqslant 60)$, because the cycling tests started right after the cell assembly, it took longer time for the cell reaction to complete and reach equilibrium, and $\Delta T$ remained very stable during the second stage $(60 \leqslant N \leqslant 300)$. However, at ca. 300 cycles, the $\Delta T$ of the cell fell off rapidly from $49.7 \%$ to $33.5 \%$. It was noticed that the extent of the increase of $T_{\mathrm{c}}$ was much larger than that of the decrease of $T_{\mathrm{b}}$ in the third stage, up to $N=540$. The

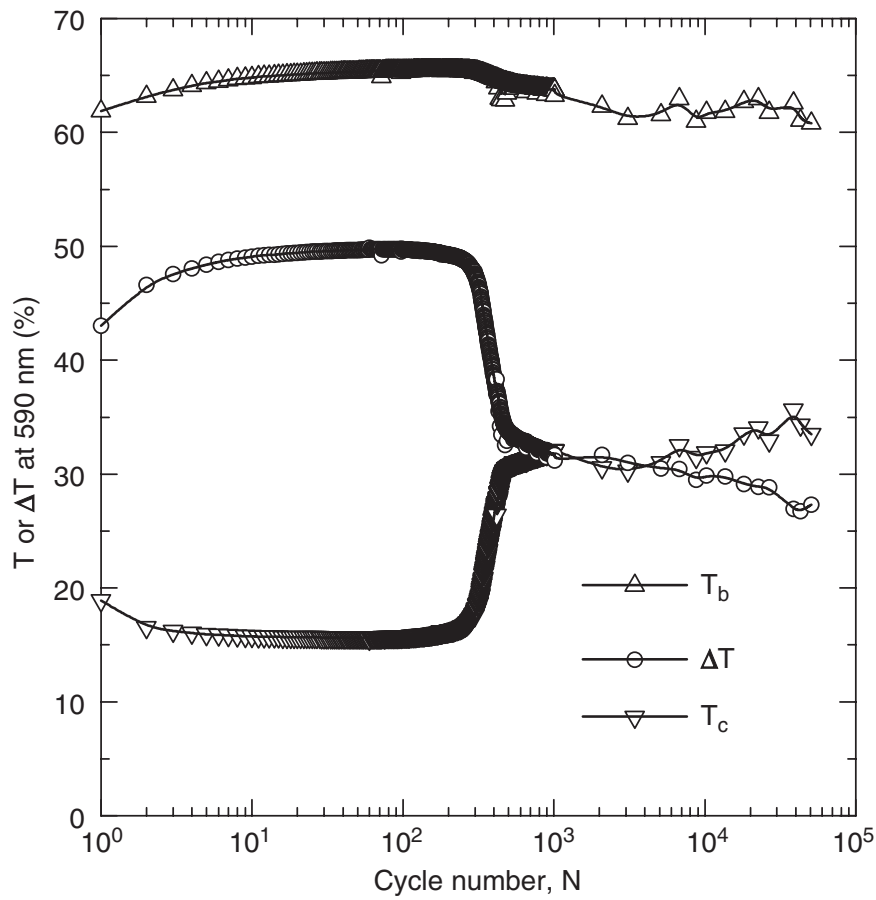

Fig. 8. Dynamic cycling stability of the cell: transmittance in the bleached state $\left(T_{\mathrm{b}}\right)$, transmittance in the colored state $\left(T_{\mathrm{c}}\right)$, and the transmittance window $(\Delta T)$ as a function of cycling number. The applied were $V_{\mathrm{c}}=-2.1 \mathrm{~V}(10 \mathrm{~s})$ for coloring and $V_{\mathrm{b}}=0.6 \mathrm{~V}(10 \mathrm{~s})$ for bleaching. The spectra data were recorded continuously during the first 1000 cycles and recorded at some specific cycles after 1000 cycles. The total cycle number was 50,640 . 
percentage of $\Delta T$ loss, based on the $\Delta T_{\max }$, is ca. $32.6 \%$ during the third stage. In the last stage $(540 \leqslant N \leqslant 50,640), \Delta T$ decreased slowly. The decay of the $\Delta T$ was only $6.2 \%$ or at an average decay rate of $0.00012 \%$ per cycle in the last stage. After a total of 50,640 cycles, the cell was still partially electroactive and the percentage of $\Delta T$ loss, based on the $\Delta T_{\max }$, was ca. $45.1 \%$ or $0.0009 \%$ per cycle. The rapid decay of $\Delta T$ between 300 and 540 cycles could be attributed to the high operating voltages. Although a maximum $\Delta T($ at $590 \mathrm{~nm})$ was obtained at $V_{\mathrm{c}}=-2.1 \mathrm{~V}$ and $V_{\mathrm{b}}=0.6 \mathrm{~V}$, applying too negative of a voltage $V_{\mathrm{c}}$ at $-2.1 \mathrm{~V}$ may cause the degradation of the PEDOT film. Besides, when a too negative $V_{\mathrm{c}}$ is applied to the cell, the PB shifts to the second redox couple, resulting in side reactions at the PEDOT electrode. This explanation is consistent with Fig. 8, which reveals that $T_{\mathrm{c}}$ increases dramatically in the third stage. Therefore, it is important to search for a safe operating voltage range before switching an ECD. The effect of operating voltage on the cell performance is discussed in a separate paper [43].

\subsubsection{Long-term at-rest stability of the ECD}

In addition to the dynamic cycling stability, the at-rest stability of the ECD is equally important. Another identical ECD was assembled and tested for its at-rest stability over a period of 107 days. The cell was cycled twice each day and stored in

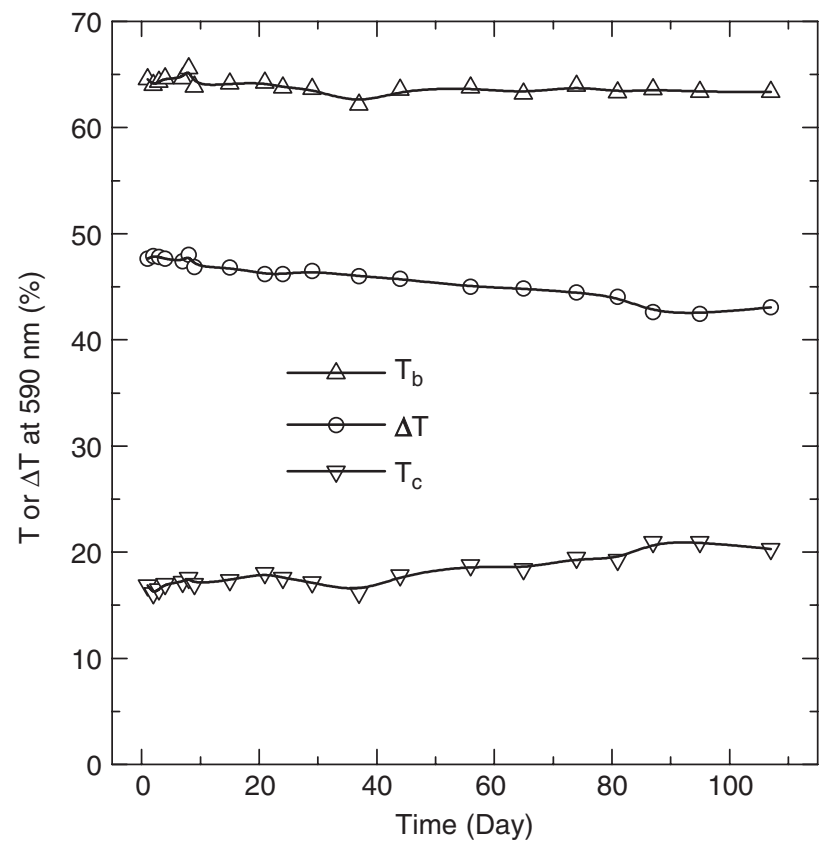

Fig. 9. At-rest stability of the cell: transmittance in the bleached state $\left(T_{\mathrm{b}}\right)$, transmittance in the colored state $\left(T_{\mathrm{c}}\right)$, and the transmittance window $(\Delta T)$ as a function of the time after assembling the cell. The applied voltages were $V_{\mathrm{c}}=-2.1 \mathrm{~V}(30 \mathrm{~s})$ for coloring and $V_{\mathrm{b}}=0.6 \mathrm{~V}(30 \mathrm{~s})$ for bleaching at each measurement. The total testing time was 107 days. 
the bleached state when at-rest. The results of the at-rest stability are shown in Fig. 9. The cell was switched at $V_{\mathrm{c}}=-2.1 \mathrm{~V}$ and $V_{\mathrm{b}}=0.6 \mathrm{~V}$, with each step lasting for $30 \mathrm{~s}$. It was found that $\Delta T$ decayed slowly over the testing period. The decay of $\Delta T$ is only ca. $9.6 \%$ over a period of 107 days. From the above results, it is inferred that this novel organic-inorganic complementary ECD not only exhibits a relatively good cycling stability but also possesses good at-rest stability. With more careful control over the coloring voltage, the system may provide opportunities for possible EC applications.

\section{Conclusions}

In this work, a new organic-inorganic complementary ECD based on PEDOT and $\mathrm{PB}$ in combination with the PMMA-based gel polymer electrolyte was proposed and tested. PEDOT is electrochemically stable in $1 \mathrm{M} \mathrm{LiClO}_{4} / \mathrm{PC}$ and reaches an anodic coloration efficiency of ca. $225 \mathrm{~cm}^{2} / \mathrm{C}$ at $590 \mathrm{~nm}$. It has also been proven that $\mathrm{PB}$ is electrochemically stable for cycling in the same organic environment, and $\mathrm{PB}$ is chosen as the counter electrode in the new ECD. With the application of $V_{\mathrm{c}}=$ $-2.1 \mathrm{~V}$ and $V_{\mathrm{b}}=0.6 \mathrm{~V}$, the PEDOT-PB ECD exhibited a deep blue-violet-to-light blue electrochromism. The transmittance window of the ECD measured at $590 \mathrm{~nm}$ was ca. $47 \%$ and a relatively high coloration efficiency of ca. $338 \mathrm{~cm}^{2} / \mathrm{C}$ was obtained. In comparison to the PEDOT-based ECDs reported in literature, the calculated coloration efficiency was reasonable, as judged by the careful recording and analysis of the current data. In addition to the high coloration efficiency, the new ECD exhibited good long-term cycling stability. In the dynamic cycling test, the value of $\Delta T$ still remained ca. $55 \%$ of its maximum value after 50,640 cycles. Moreover, the results of the at-rest stability test showed that the decay of the $\Delta T$ was only $9.6 \%$ over a period of 107 days. It is hoped that the high coloration efficiency and the good cycling and at-rest stabilities of the PEDOT-PB ECD will make it attractive for real world applications.

\section{Acknowledgment}

The authors wish to thank RiTdisplay Corporation, Hsinchu Industrial Park, Taiwan, for providing the conductive ITO glass substrates. This research was supported by the National Research Council of the Republic of China under Grants NSC 92-2623-7-002-005-NU and NSC 92-2214-E002-037. We also want to thank the support received from the ITRI and the NTU-ITRI Nano Center.

\section{References}

[1] P.M.S. Monk, R.J. Mortimer, D.R. Rosseinsky, Electrochromism: Fundamentals and Applications, VCH, Weinheim, Germany, 1995.

[2] R.D. Rauh, Electrochim. Acta. 44 (1999) 3165-3176. 
[3] K. Itaya, K. Shibayama, H. Akahoshi, S. Toshima, J. Appl. Phys. 53 (1982) 804-805.

[4] [a] F.G.K. Baucke, in: C. M. Lampert, C.G. Granqvist (Eds.), SPIE Institute Series, IS4, 1990, pp. 518-538.

[b] H.J. Byker, in: K.-C. Ho, D. M. MacArthur (Eds.), Proceedings of the Symposium on Electrochromic Materials, The Electrochemical Society, Pennington, NJ, 1994, pp. 3-13.

[5] V.D. Neff, J. Electrochem. Soc. 132 (1985) 1382-1384.

[6] C.M. Lampert, Sol. Energy Mater. Sol. Cells 52 (1998) 207-221.

[7] T. Miyamoto, M. Ura, S. Kazama, T. Kase, Y. Maeda, US Patent 4,645,307, 1987.

[8] M. Kawai, H. Miyagi, M. Ura, US Patent 4,801,195, 1989.

[9] K.-C. Ho, T.G. Rukavina, C.B. Greenberg, J. Electrochem. Soc. 141 (1994) 2061-2067.

[10] J. Minoura, T. Uemura, S. Takahashi, T. Ito, K. Okabayashi, US Patent 5,054,895, 1989.

[11] B.P. Jelle, G. Hagen, R. Ødegård, Electrochim. Acta 37 (1992) 1377-1380.

[12] A.M. Rocco, M.A. De Paoli, A. Zanelli, M. Mastragostino, Electrochim. Acta. 41 (1996) 2805-2816.

[13] H.J. Byker, US Patent 4,902,108, 1990.

[14] M.-N. Collomb-Dunand-Sauthier, S. Langlois, E. Genies, J. Appl. Electrochem. 24 (1994) $72-77$.

[15] C. Arbizzani, M. Mastragostino, L. Meneghello, M. Morselli, A. Zanelli, J. Appl. Electrochem. 26 (1996) 121-123.

[16] T.A. Skotheim, R.L. Elsenbaumer, J.R. Reynolds (Eds.), Handbook of Conducting Polymers, second ed., Marcel Dekker, New York, 1998.

[17] F. Jonas, G. Heywang, W. Schmidtberg, J. Heinze, M. Dietrich, US Patent 5,035,926, 1991.

[18] G. Heywang, F. Jonas, Adv. Mater. 4 (1992) 116-118.

[19] F. Jonas, L. Schrader, Synth. Methods 41-43 (1991) 831-836.

[20] M. Granström, M. Berggren, O. Inganäs, Science 267 (1995) 1479-1481.

[21] L.S. Roman, M.R. Andersson, T. Yohannes, O. Inganäs, Adv. Mater. 9 (1997) 1164-1171.

[22] H. Yamato, M. Ohwa, W. Wernet, J. Electroanal. Chem. 397 (1995) 163-170.

[23] J.C. Gustafsson, B. Liedberg, O. Inganäs, Solid State Ionics 69 (1994) 145-152.

[24] S.A. Sapp, G.A. Sotzing, J.L. Reddinger, J.R. Reynolds, Adv. Mater. 8 (1996) 808-811.

[25] S.A. Sapp, G.A. Sotzing, J.R. Reynolds, Chem. Mater. 10 (1998) 2101-2108.

[26] M.A. De Paoli, G. Casalbore-Miceli, E.M. Girotto, W.A. Gazotti, Electrochim. Acta. 44 (1999) 2983-2991.

[27] M.A. De Paoli, A.F. Nogueira, D.A. Machado, C. Longo, Electrochim. Acta. 46 (2001) 4243-4249.

[28] D. DeLongchamp, P.T. Hammond, Adv. Mater. 13 (2001) 1455-1459.

[29] V.D. Neff, J. Electrochem. Soc. 125 (1978) 886-887.

[30] D. Ellis, M. Eckhoff, V.D. Neff, J. Phys. Chem. 85 (1981) 1225-1231.

[31] K. Itaya, I. Uchida, Acc. Chem. Res. 19 (1986) 162-168.

[32] D.E. Stilwell, K.H. Park, M.H. Miles, J. Appl. Electrochem. 22 (1992) 325-331.

[33] H. Inaba, M. Iwaku, K. Nakase, H. Yasukawa, I. Seo, N. Oyama, Electrochim. Acta. 40 (1995) $227-232$.

[34] A.L. Crumbliss, P.S. Lugg, N. Morosoff, Inorg. Chem. 23 (1984) 4701-4708.

[35] N. Leventis, Y.C. Chung, J. Electrochem. Soc. 138 (1991) L21-L23.

[36] O. Bohnke, C. Rousselot, P.A. Gillet, C. Truche, J. Electrochem. Soc. 139 (1992) 1862-1865.

[37] S.A. Agnihotry, Pradeep, S.S. Sekhon, Electrochim. Acta 44 (1999) 3121-3126.

[38] Q. Pei, G. Zuccarello, M. Ahlskog, O. Inganäs, Polymer 35 (1994) 1347-1351.

[39] M. Dietrich, J. Heinze, G. Heywang, F. Jonas, J. Electroanal. Chem. 369 (1994) 87-92.

[40] C. Carlberg, X. Chen, O. Inganäs, Solid State Ionics 85 (1996) 73-78.

[41] A. Kumar, D.M. Welsh, M.C. Morvant, F. Piroux, K.A. Abboud, J.R. Reynolds, Chem. Mater. 10 (1998) 896-902.

[42] C.L. Gaupp, D.M. Welsh, R.D. Rauh, J.R. Reynolds, Chem. Mater. 14 (2002) 3964-3970.

[43] T.-S. Tung, K.-C. Ho, Adv. Mater. submitted for publication. 